NBER WORKING PAPER SERIES

\title{
PHYSICIAN FINANCLAL INCENTIVES AND CESAREAN SECTION DELIVERY
}

\author{
Jonathan Gruber \\ Maria Owings
}

Working Paper No. 4933

\author{
NATIONAL BUREAU OF ECONOMIC RESEARCH \\ 1050 Massachusetts Avenue \\ Cambridge, MA 02138 \\ November 1994
}

We are grateful to Ed Bacon, Peter Diamond, Victor Fuchs, Marty Gaynor, Tom McGuire, Joe Newhouse, Robert Pokras, Jim Poterba, Richard Zeckhauser, Jon Skinner, seminar participants at MIT, Harvard, and the NBER, and to the editor and two anonymous referees for helpful comments. This paper is part of NBER's research programs in Health Care and Public Economics. Any opinions expressed are those of the authors and not those of the National Center for Health Statistics or the National Bureau of Economic Research.

(C) 1994 by Jonathan Gruber and Maria Owings. All rights reserved. Short sections of text, not to exceed two paragraphs, may be quoted without explicit permission provided that full credit, including () notice, is given to the source. 


\title{
PHYSICIAN FINANCIAL INCENTIVES
}

AND CESAREAN SECTION DELIVERY

\begin{abstract}
The "induced demand" model states that in the face of negative income shocks physicians may exploit their agency relationship with patients by providing excessive care in order to maintain their incomes. We test this model by exploiting an exogenous change in the financial environment facing obstetrician/gynecologists during the 1970s: declining fertility in the U.S. We argue that the $13.5 \%$ fall in fertility over the $1970-1982$ period increased the income pressure on ob/gyns, and led them to substitute from normal childbirth towards a more highly reimbursed alternative, cesarean delivery. Using a nationally representative micro-data set for this period, we show that there is a strong correlation between within state declines in fertility and within state increases in cesarean utilization. This correlation is robust to consideration of a variety of alternative hypotheses, and appears to be symmetric with respect to periods of fertility decline and fertility increase.
\end{abstract}

Jonathan Gruber

Department of Economics, E52-274c

M.I.T.

50 Memorial Drive

Cambridge, MA 02139

and NBER
Maria Owings

National Center for Health Statistics 3700 East West Highway

Hyattsville, MD 20782 
A standard model of physician behavior in the health economics literature is that of "induced demand". This model states that in the face of negative income shocks physicians may exploit their agency relationship with patients by providing excessive care in order to maintain their incomes. Such a model has traditionally been tested by assessing the effects on the utilization of medical procedures of two alternative changes in the environment facing physicians. The first is reductions in the fees paid to physicians, generally by government payers. The second is variations in the physician/population density across areas; increased density lowers the income of the existing stock of physicians, and will lead to increased utilization of medical procedures in an inducement-type model.

Each of these approaches faces important problems, however. Foe changes cannot identify supply responses because there may be a contemporaneous demand response to changing prices; that is, if quantity rises when fees fall, this could reflect either induced or true increases in demand. Using fee changes to identify inducement also raises the problem that substitution and income effects go in opposite directions; even if there is no measured utilization response, there may be inducenent, but substitution and income effects may simply be cancelling. Studies that use physician density differences to proxy for income shocks also face a fundamental identification problem. If there is some unobserved area characteristic which is correlated with taste for medical interventions, an area will feamure boch hipher procedure utilization and more physicians, regardless of the extent of demand inducement: An obvious candidate for such an omitted variable is the average coinsurance rate in the area.

In this paper, we propose a new means of identifying the effect of induced demand on procedure utilization. We exploit a plausibly exogenous change in the financial environment facing 
obstetrician/gynecologists during the 1970s: declining fertility in the U.S. Fertility (births $/ 100$ population) fell by $13.5 \%$ during the $1970-1982$ period. We argue that declining fertility increased the income pressure on ob/gyns, and led them to substitute from normal childbirth towards a more highly reimbursed atternative: cesarean delivery. Used in only $5.5 \%$ of births in 1970 , cesarean delivery rose by over $240 \%$ over the subsequent 12 years, and it is now the second most frequently performed major surgical procedure in the U.S., with a rate of 23.5 cesarean deliveries per 100 births.' This time series correlation between the fertility decline and the cesarean utilization increase raises the possibility that inducement played an important role in the substiution of cesarean delivery for normal childbirth.

The primary purpose of this paper is to test for a causal role of financial incentives in the use of cesarean delivery over the 1970-1982 period. We do so by exploiting the dramatic change in fertility patterns across the U.S. states during this era. Conditional on the characteristics of the mother and of the birth, statewide fertility changes should provide exogenous measures of the financial pressure on ob/gyns in that state. Thus, we ask: in states where fertility was falling the most, did cesarean delivery rise the most?

Our test is carried out using a rich dataset of individual birth records from the 1970-1982 period. The National Hospital Discharge Survey (NHDS) is a nationally representative survey of hospitais which collects information, for a sample of discharges, on the nature of the hospital stay, procedures performed during that stay, and the demographic characteristics of the patient. There is dats on approximately 20,000 deliveries annually from a wide cross-section of hospitals. We match this data on individual births to information on changes in fertility levels by state and year, and examine the effect of within state changes in fertility on the use of cesarean delivery. We use both

\footnotetext{
'Unpublished tabulations, National Center for Health Statistics.
} 
individual level and suate level data to control for a number of other characteristics of mothers and birchs, such as age, birch order, and infant health, which may be spuriously correlated with both the fertility rate and the use of cesarean delivery.

To summarixe, we find a strong correlation between within-state fertility declines and withinstate increases in cesarean section delivery rates: a $10 \%$ decline in the fertility rate is associated with 2 0.97 percentage point increase in the cesarean delivery rate. This finding is robust to a wide variety of specification checks. It implies that financial incentives do play an important role in the substitution of cesarean delivery for normal childbirth. This role was a small one relative to the rapid growth in cesarean delivery, however; increased ob/gyn income pressure can only explain between $16 \%$ and $32 \%$ of the substitution of cesarean delivery for normal childbirth during this era.

We begin, in Part I, by discussing the causes and consequences of the diffusion of cesarean childbirh in the 1970s. In Part II, we summarize the literanure on the induced demand hypothesis, and present a brief model which notes the implications of this hypothesis for the use of cesarean delivery when the fertility rate falls. Part III describes the data sources and the empirical framework used. Part IV presents the basic results and specification checks. Part $\mathrm{V}$ assesses whether cesarean delivery responded asymmetrically to fertility rises and falls. Part VI concludes.

\section{Part I: Background on Cesarean Delivery}

\section{Cesarean Delivery in the United States}

The upper line in Figure 1 charts the growth in the cesarean section rate (c-sections per 100 birchs) nationally over the 1970 to I991 period. The rate doubled from 1970 to 1975 , and doubled again by 1984 . Utilization of the procedure flattened out in the mid-1980s, and fell somewhat at the end of the decade. This rapid growth in c-section utilization was not restricted to any particular 
region, type of hospital, race, or age group (Placek and Taffel, 1980). The lower line shows the growth in the primary cesarean section rate; until recently, women who had received previous csections were almost universally c-sectioned on all future births. ${ }^{2}$ The trend is similar, although a growing fraction of cesarean births over time is due to repeat cesareans.

There is no consensus view as to the cause of this rapid increase in cesarean utilization. Perhaps the most frequently cited explanation is the introduction of technologies for diagnosing fetal distress, such as electronic fetal monitoring. The percentage of deliveries with no reported complication fell from $70 \%$ in 1970 to $39 \%$ in 1984 (Shiono et al., 1987), and Williams and Hawes (1979) document a strong correlation between the percent of deliveries by cesarean-section and the proportion of labor electronically monitored across California hospitals in 1977 . However, cesarean section rates grew within diagnosis as well. In 1970, 11.6\% of breech presentations were delivered by c-section; by 1984, 80 \% were delivered in this fashion (Shiono et al., 1987). The NIH (1981) shows that almost one-half of the growth in primary cesarean rates was within diagnosis growth.

Another important cause of c-section adoption was thought to be the legal environment. Marieskind (1979) reports that the most frequent reason given by physicians for performing a cesarean section was the threat of a malpractice suit. She cites a National Association of Insurance Commissioners study which reports that, in 1975-76, ob/gyns faced 10 times the probability of suit of other physicians. Recent econometric work which examines the regional correlation between malpractice "threax", as measured by malpractice premiums or previous malpractice clains paid, and

\footnotetext{
${ }^{2}$ In $1970,98.3 \%$ of women with previous caesareans received c-sections; by 1984 , the rate had fallen slightly to $96.1 \%$ (Shiono et al., 1987).
} 
cesarean utilization has produced mixed results, however. ${ }^{3}$

\section{Financial Incentives for Cesarean Delivery}

The hypothesis to be tested in the empirical work is that declining fertility led to a substitution wowards cesarean delivery, in order to alkeviate the income pressure on ob/gyns. A necessary precondition for this hypothesis is that cesareans be reimbursed more highly than normal childbirth, which has traditionally been true. The Health Insurance Association of America (1989) reports that physician charges for cesarean delivery in 1989 were $\$ 2,053$, compared to $\$ 1,492$ for vaginal delivery. While no such systematic data are avajlable for the 1970s, Marieskind (1979) reports fee differences for a sample of cities for the late 1970's: the average differential was approximately $40 \%$, which is similar to the 1989 differential.

These higher teimbursement levels are not necessarily justified by increased physician inputs. In terms of the time invesument only, cesarean delivery is much more efficient for the ob/gyn; unlike normal childbirth, cesarean deliveries can be scheduled in advance, and they often take less time than a normal childbirth with extended labor. Of course, cesarean delivery is a more difficult procedure. However, the 1993 revision of the resource-basod relative value scale (RBRVS), which measures physician workloads by the product of intensity and time, concluded that the workload for vaginal delivery is actually bigher than that of cesarean delivery (Keeler and Brodie, 1993).

\footnotetext{
'See Keeler and Brodie (1993) for a review, and Localio et al. (1993) and Tussing and Wojotowycz (1992) for results. Furthermore, none of these studies has been able to surmount the problem that there may be omitted regional variables correlated with both of the malpractice threat measures and cesarean utilization.

This discussion does not account for any disutility from the extra training necessary for cesarean delivery; however, Marieskind (1979, p. 121) notes that obstetricians were not even trained in vaginal breech delivery by the late 1970 s, so that these training costs have presumably already been paid by practicing ob/gyns.
} 
Furthermore, the structure of private insurance coverage during the 1970s may have contributed to the financial rewards to cesarean delivery. A commonly accepted fearure of health insurance benefits before the mid-1970s was limited coverage for childbirth. Maternity coverage was sometimes excluded from basic health benefits; if included, it was often subject to flat rate cash amount limits regardless of the cost of delivery. Many policies, however, limited coverage of normal childbirth only, and fully covered the costs of cesarean delivery. In this case, there would be an incentive for the physician to substitute cesarean childbirth for normal delivery. This differential coverage was outlawed by several state mandates in the 1975-1978 period and then by Federal stanue in October, 1978 (Gruber, 1992). ${ }^{3}$

There have been two types of previous studies of the role of financial incentives in the use of cesarean delivery. The first focuses on differences in cesarean utilization by insurance coverage rype. The relative rewards for cesarean delivery for the privately insured are much higher than for the publicly insured or uninsured. Using data in American College of Obsteuricians and Gynecologists (1989), we calculate that the aver age reimbursement differential for cesarean delivery in 1989 under Medicaid was only $\$ 230$, which is $40 \%$ as large as the average differential in physician charges discussed above. For uninsured patients, the financial rewards may be lower still,

\footnotetext{
'In theory, these state and federal laws changed the financial incentives of physicians in a testable way, by levelling the playing field between normal childbirth and cesarean delivery. This test runs into two problems in practice, however. First, while most private insurance did limit coverage of normal childbirth, many policies limited coverage of cesarean delivery as well. Gruber (1992) finds that $30 \%$ of private insurance plans in 1977 paid less than the physician's usual charges for childbirth than for other procedures. Thus, these laws, which typically introduced first dollar coverage of a physician's usual charge for both normal and cesarean childbirth, simultaneously increased the incentives for both types of delivery. In addition, as noted below, we cannot identify privately insured patients in our data before 1977, which does not leave much variation in the legal environment before the federal statute of October, 1978. Perhaps due to these problems, we were unable to find significant effects of these law changes on cesarean utilization. The inclusion of these variables, however, did not affect the coefficient on fertility in the regressions reported below.
} 
as there is a reasonable probability that the bill will not be paid at all. Epstein et al. (1989) find for a sample of Massachuseas hospitals that $80 \%$ of total charges to self-pay patients are not paid. While similar figures for physicians charges are not available, this suggests that physicians may be unable to recoup from uninsured patients the differential charge for doing a cesarean delivery.

Stafford (1990) examined cesarean rates by payment source in a sample of California hospitals, and found resulis which lined up quite well with these financial incentives: cesarean rates were highest for those with private insurance, followed by the publicly insured, and then the uninsured. It is difficult, however, to draw causal inferences from this fact because there may be omitted characteristics by payer class which are correlated with the cesarean decision (ie. birch severity).

The second test focuses on the supposition, made for example by Marieskind (1979), that a declining fertility rate and increases in ob/gyn density may have led to increased use of cesarean delivery in the 1970s; this point is developed theoretically below. Tussing and Wojotowycz (1992), examining New York data, find no evidence that cesarean delivery rates are higher where there is a higher ob/gyn density. Once again, however, such a study suffers from the fact that there may be omitted regional differences which are correlated with both higher ob/gyn density and cesarean utilization.

\section{Consequences of C-Secrion Diffusion}

One porential cause of the diffusion of cesarean sections was the belief that they were instrumental in improving birth outcomes. There is a strong time series correlation between the rapid improvement in birth outcome in the U.S. and the diffusion of cesarean sections. From 1968 to 1983, the infant mortality rate in the U.S. was halved; this is the exact time period that saw rapid 
diffusion of cesarean sections. However, Marieskind (1979) is critical of this interpretation of the time series data, noting that there were many other technological advances in the treatment of childbirth, such as the development of neonatal intensive care units.

Micro-data evidence on the effectiveness of cesarean delivery is mixed. Williams and Hawes (1979) studied a sample of hospitals in California in 1977, and found a correlation between increased use of technology in childbirth, including fetal monitoring and cesarean delivery, and the demographically-adjusted perinatal mortality rate. On the other hand, in a sample of mature ( $>2500$ grams) breech births in New York City, the NIH (1981) found no change in survival probabilities over time, despite a sizeable rise in the cesarean delivery rate. And Finkler and Wirtschafter (1993) find no relationship between cesarean section use and risk-adjusted birth outcomes across their sample of eight California hospitals.

While we are unaware of any randomized clinical trials to evaluate the effectiveness of cesarean sections, there have been several trials which randomly assigned the availability of electronic fetal monitoring. Three of the four studies found that monitoring was associated with higher c-section rates, but no improvements in perinatal outcomes (NIH, 1981).

Cesarean delivery is also more costly than vaginal childbirth, along two dimensions. The first is physiological costs. Maternal mortality is very low overall (approximately 1 death per 10,000 births), but it is two to four times as high for cesarean as for vaginal deliveries (NIH, 1981). There are a number of less severe but more common risks as well, such as post-operative infection and hemorrhage. There are also potential physiological costs to the infant, such as respiratory distress syndrome in infants who are delivered premahurely by c-section (Marieskind, 1979).

\footnotetext{
'More recent data on maternal mortality may show a smaller differential between vaginal and cesarean deliveries.
} 
The second is financial cosis. In 1989, the total (doctor and hospital) costs of a cesarean delivery were $66 \%$ higher than the costs of a normal delivery (Health Insurance Association of America, 1989). In that year, there were 938,000 cesarean section deliveries in the U.S. (Graves and Kozack, 1992). If these deliveries had been as costly as the average normal childbirth, then this accounts for a differential of $\$ 2.7$ billion dollars in medical spending. While this is clearly an upper bound, since cesarean deliveries are likely to be more severe, it does highlight the large differential expendiare on cesarean delivery in the U.S.

\section{Part II: Induced Demand - Theory and Evidence}

\section{An Inducemens Model}

The induced demand hypothesis has been explored by a number of studies over the past twenty years. The building block of this theory is the notion that, as the agent of the uninformed parient, physicians are able to determine the level of demand for their product. 'Physicians are generally posited to have utility functions which depend positively on their income, leisure, and on delivering the "appropriate" amount of care. The last factor can enter either through the physician's "internal conscience" (McGuire and Pauly, 1991), or as a result of a reputation process by which physicians who excessively induce demand are punished through fubure reductions in true patient demand (Dranove, 1988).' Inducement can be defined as the deviation of treatment levels from that which equates the marginal benefits and costs to patients (Fuchs, 1978).

A natural implication of inducement models is that a fall in the birth rate will lead to adoption

\footnotetext{
'Dranove (1988) correctly notes that induced demand models can be equally well applied to other agency relationships between buyers and (expert) sellers.

'For earlier models of this type of provider behavior, see Evans (1974) and Newhouse (1970).
} 
of more highly reimbursed procedures such as cesarean delivery. This is readily illustrated in a simple inducement model, along the lines of McGuire and Pauly (1991).' We take the number of births as given to the ob/gyn. ${ }^{10}$ We also assume that the only margin for inducement is to increase intensity by shifting the nawure of the delivery from a normal childbirth to a cesarean delivery. This is not strictly true, since ob/gyns appear to earn only about one-half of their income from obstetrics on average." Introducing other dimensions of inducement into the model would not change the direction of our prediction, however; whether inducement in fact takes place through the type of delivery is ultimately an empirical question.

We posit that the ob/gyn has a utility function of the form:

$$
\mathbf{U}=\mathbf{U}(\mathbf{Y}, \mathbf{I})
$$

where $\mathrm{Y}$ is full income, earnings minus the value of foregone leisure, and $\mathrm{I}$ is the extent of "inducement", which causes the physician disutility through either the "internal conscience" or "demand reduction" channels $\left(U_{Y}>0, U_{I}<0 ; U_{Y Y}, U_{I I}<0\right)$. The number of births is $B$, and the level of inducement per birth is $i$, so that $I=B i$; the totai disutility from inducement depends on the total amount of inducement across all patients. The fraction of cesarean deliveries is $\alpha(i), \alpha^{\prime}>0$, $\alpha^{\prime \prime}=0$. Thus, the budget constraint is:

\footnotetext{
Te are grateful to Tom McGuire for suggesting this formulation of the McGuire/Pauly model for our case.

${ }^{10}$ This may be particularly inappropriate in the 1970 s, since most insurance plans did not cover the cost of normal childbirth, so that demand may have been somewhat price elastic. However, even if the number of births for a given ob/zyn is price elastic, changes in the stock of births in the state still provide an exogenous shock to the income of the average ob/gyn in that state.

"ACOG (1992) reports that $56 \%$ of ob/gyns earn at least $40 \%$ of their incomes, and $76 \%$ earn at least $25 \%$ of their incomes, from obstetrics. Furthermore, data in ACOG (1992) indicates that 55.8\% of ob/gyn visits are for pre-natal or post-natal care, and the American Medical Association (AMA, 1992) reports that one-half of all surgical procedures performed by ob/gyns are childbirth.
} 
(2) $\quad \mathrm{Y}=\mathrm{Y}_{\mathbf{v}} \mathrm{N}+\mathrm{Y}_{\mathrm{c}} \mathrm{C}$.

$\mathrm{C}=\mathrm{B} \alpha(\mathrm{i})$

$\mathrm{N}=\mathrm{B}(1-\alpha(\mathrm{i}))$

where $N$ is the number of normal births, and $C$ is the number of cesareans. $Y_{n}$ and $Y_{c}$ are the full incomes from performing normal and cesarean deliveries, respectively. We assume that $Y_{c}>Y_{n}$. That is, we assume that the reimbursement premium for cessrean deliveries is sufficiently high to compensate the physician for any loss in keisure from performing a cesarean. This scems reasonable given the data presented above that cesarean fees are much highet, that cesarean delivery takes less time, and that the increased difficulty of cesarean delivery does not, in the judgement of the experts who developed the RBRVS, compensate for the time reduction.

We follow McGuire and Pauly in assuming separable utility. The first order condition becomes:

$$
U_{Y} \alpha^{\prime}\left[Y_{c}-Y_{d}\right]+U_{1}=0
$$

That is, the physician trades off the net disutility from inducement against the net utility from increasing income through shifting to cesarean delivery. Suppose now that the number of births, B, is exogenously roduced. Fully differentiating (3), we obtain:

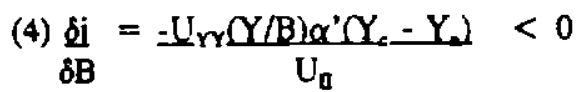

That is, 2s births fall, inducement per birth rises, so that the rate of cesarean delivery rises. We discuss the magnitude of this incentive in more detail in Part III.

Physician Type, Mobiliny, and Enrry

Two important further assumptions underlie this model. First, we have assumed that all births are delivered by ob/gyns. If in fact a non-trivial share of births are delivered by practitioners 
other than ob/gyns, then ob/gyns may be insulated from changes in the birth rate. That is, deliveries by non-ob/gyns may fully absorb fluctuations in the number of births, so that ob/gyns have no change in inducement incentives. If only ob/gyns perform cesarean deliveries, then this scenario could in fact lead to a spurious (from our perspective) negative correlation between fertility changes and cesarean utilization.

The vast majority of births, however, are delivered by ob/gyns. During our sample period, over $99 \%$ of all births were delivered by a physician in a hospital setting (Vital Statistics). Of physicians, the AMA (1993) reports that ob/gyns perform 13.8 deliveries per month, while general and family practitioners (the second largest category) perform only 0.7 . The number of general and family practitioners is approximately twice that of the number of ob/gyns, so that ob/gyns deliver over $90 \%$ of all babies by this calculation. Similarly, using data on the fraction of dollars derived from delivery services for a large Blue Cross/Blue Shield plan in a major U.S. city, we tabulate that $87 \%$ of delivery dollars were attributable to ob/gyns.

Second, we have assumed that ob/gyns are immobile. If ob/gyns are mobile, then their location may respond to fertility changes in a way which partially offsets the inducement incentives documented above. In fact, it does appear that ob/gyns respond to changes in fertility rates in making their locational decisions; a regression over the 1970-1982 period of the log of the number of ob/gyns on the log of the fertility rate, including a full set of state and year dummies, yields a significant and positive coefficient of roughly 0.2 . To the extent that ob/gyns are offsetting fertility declines by their locational choices, it will lead to a smaller effect of fertility changes on the use of cesarean delivery in the empirical work below. Whether these locational choices are sufficient to 
fully undo the need for inducement in response to falling fertility is an empirical question. ${ }^{12}$

There is also a simple fact which seems to contradict the contentions of this model: entry into obstetrics and gynecology continued unabated during the era of fertility decline, with ob/gyns per capita increasing by $38 \%$ from 1970 to 1982 . If fertility decreases were increasing the financial pressure on ob/gyns, why should they have continued to enter this field at such a rapid rate? There are a number of other factors, however, which may have affected the altractiveness of medical professions during this era, such as the general decline in returns to higher education of the 1970s (Freeman, 1976). A more relevant question is whether entry into this field relative to other medical sub-specialties responded to fertility changes. In fact, there is a strong positive correlation $(6=0.75)$ between annual fertility rates and the ratio of ob/gyns to other physicians in the U.S. over the 19701982 period. This suggests that, conditional on choosing to enter the medical profession, individuals were considering the relative rewards of this field in making their specialty decision.

\section{Induced Demand - Past Evidence}

As noted above, induced demand effects have been posed and tested in two different contexts.

The iirst is reductions in the fees paid to physicians, generally by government payers. In this case, inducement operates through both the substitution and income effects, so that the net effect on the

\footnotetext{
${ }^{12}$ It is possible that ob/gyn mobility could lead to a correlation between fertility and the cesarean rate that was independent of induced demand. Suppose that there were two types of ob/gyns, high quality and low quality, and that high quality ob/gyns performed more cesareans. If the fertility fall leads to a fall in demand for low quality ob/gyns, they may leave the state, raising the measured cesarean delivery rate through a compositional effect. Given the estimated mobility response, however, this effect will in general not be large enough to explain our findings below. For example, if initially $1 / 2$ of ob-gyns are low quality and do $10 \%$ cesarean deliveries and $1 / 2$ are high quality and do $20 \%$ cesarean deliveries, and there is a $10 \%$ fertility decline which leads to a $2 \%$ net outflow of ob/gyns, and all of the outflow comes from the low quality sector, the cesarean delivery rate would rise from $15 \%$ to $15.1 \%$. This is much smaller than the effect estimated below, which is on the order of a 1 percentage point rise in the c-section rate for a $10 \%$ fertility fall.
} 
quantity of services is unclear. However, most previous studies have tested for inducement by assessing whether quantity increased when fees were reduced (that is, under the assumption that income effects dominate substinution effects); in the limit, with a "target income", quantity increases fully undo the price reductions.

There is some evidence that fee reductions lead to increases in quantities, although the magnitude of inducement is very uncertain. The strongest evidence for induced quantity increases is Rice's (1984) study of a Medicare fee reduction in Colorado; he found that a $10 \%$ decline in physician reimbursements led to a $6.1 \%$ increase in intensity of medical services and a $2.7 \%$ increase in intensity of surgical services. However, a similar study by Hurley, Rice, and Labelle (1990) for Ontario found mixed responses to fee changes across procedures. Evidence from the experiences of the U.S. and Canada with fee controls offers a similarly mixed picture of the role of induced demand; see Wedig, Mitchell, and Cromwell (1989), Feldman and Sloan (1988, 1989), and Rice and Labelle (1989) for a discussion.

The second context for testing induced demand is the response of procedure use to variations in the physician/population density across areas. Evidence on the use of surgery in response to an increased supply of surgeons is presented in Fuchs (1978) and Cromwell and Mitchell (1986). Both authors looked at a cross section of locations over several years, and found strong evidence for demand inducement; the latter findings are about one-third as large as the former. Birch (1989) and Grytten ef af (1991) also find very strong positive relationships between dentists/capita and utilization of dental services. ${ }^{13}$

As discussed in the introduction, both of these methodologies face important identification

\footnotetext{
${ }^{13}$ For reviews of the induced demand literature, see Feldman and Sloan (1988) or Dranove and Wehner (1994).
} 
problems. The problem of omitted variables correlated with physician density is discussed in Auster and Oaxaca (1981), Phelps (1986), and Feldman and Sloan (1988). Both Fuchs and Cromwell and Mitchell attempt to surmount this problem by finding instruments correlated with physician density, such as population distribution across metro and non-metro areas, average wages, and other socioeconomic characteristics of the area. It is unclear, however, whether these instruments are also uncorrelated with taste for surgery; wealthier or more urban areas may feature different average coinsurance rates. ${ }^{14}$

In this paper, we propose an alternative means of identifying an inducement effect for ob/gyns: using changes in the fertility rate. The model above shows that changes in fertility will have inducement-type incentives. And, conditional on the characteristics of the mother and the birth, statewide changes in fertility should be an exogenous shock to the income of ob/zyns. In the empirical work below, we will consider this exogeneity assumption in more detail, by controlling for a number of potential omitted correlates of fertility rate changes and cesarean delivery rates.

In some specifications below, we will also follow the previous literature in using changes in ob/gyn density to proxy for income pressure. We potentially improve on previous estimates of the effect of physician density on procedure utilization by including location (state) fixed effects in the regression, thus controlling for any omitted variables which are constant over time. Nevertheless, some of the identification problems noted by the critics of this approach are difficult to surmount simply by using within-area changes. Thus, we will primarily rely on fertility changes to proxy income pressure on ob/gyns in the estimation.

\footnotetext{
${ }^{14}$ This criticism is levelled most damningly by Dranove and Wehner (1994), who find that, using a similar instrumental variables methodology to Mitchell and Cromwell (1986), increasing the number of ob/gyns in an area increases the number of births!
} 


\section{Part III: Data and Empirical Framework}

Dase

Our primary data source is the National Hospital Discharge Survey (NHDS) conducted by the National Center of Health Statistics (NCHS) annually since 1965. This is a nationally representative survey of over 400 hospitals, which contains information on approximately 200,000 discharges in each year. The survey collects information on some limited demographic characteristics of the patient, features of the hospital, primary and secondary diagnoses, and primary and secondary procedures. We use information on patients with a primary diagnosis of childbirth in the years 1970-1982; the final sample consists of over 250,000 births. The public use file of the NHDS only identifies the region of the hospital. These files were augmented with stare identifiers, and all analysis was carried out at the NCHS. ${ }^{15}$

The means for the dataset are presented in Table 1, for both the full dataset, and for those births which did and did not get delivered by c-section. ${ }^{16}$ Approximately $11.9 \%$ of births are by cesarean section over this time period. While the majority of births are to younger women, the majority of $c$ "sections are performed on older women. There are relatively few deliveries in forprofit hospitals in this time period. The most striking differences between the cesarean and noncesarean columns are in the figures for hospital size and for severity codes; cesareans are much more likely in large hospitals, and are strongly correlated with a complicated delivery. Since our identifying variation will come from state level changes in fertility, it is comforting to note that we

\footnotetext{
${ }^{15}$ The NHDS does not collect data for three low population states so these states were dropped from the analysis. The NHDS also provides weights to capture the probability that a given discharge was sampled. All results were computed both weighted and unweighted, and were very similar in every case. The results reponted below are unweighted,

${ }^{16}$ The NHDS only identifies expected source of payment from 1977 onwards, so we do not use that variable in our basic analysis. We do use it in one specification check below.
} 
have a reasonably large average sample size of deliverics for each state/year. The mean number of deliveries by state/year is 837 , and the value ranges from a minimum of 17 to a maximum of 2767 .

In order to examine the effect of fertility on the use of cesarean delivery, we exploit the substantial variation across states in fertility changes in this era. Data on the number of births in each state and year is available from the NCHS' Visal Statistics of the United Stases. ${ }^{17}$ Figure 2 graphs the average fertility rate, births per 100 population, by year for our sample period. There is a suriking decline in fertility from 1970-75, and a moderate rise from 1977-1982. Over the entire period, fertility falls from 1.84 births $/ 100$ persons to 1.59 births $/ 100$ persons, a decline of $13.5 \%$." These national trends mask substantial heterogeneity in fertility changes within states over ime. Figures $3 \mathrm{~A}$ and $3 \mathrm{~B}$ illustrate two examples of this heterogeneity. In both North Carolina and Kansas, there were steep fertility declines in the early years of the sample period. However, while fertility declined until 1976 and was flat thereafter in North Carolina, fertility dropped much more rapidly in Kansas, and rose thereafter, so that by 1982 fertility levels were actually higher than in 1970. Approximately $10 \%$ of the total variation in fertility rates from 1970-1982 is within state variation in fertility over time. Ranking states by their fertility rates in 1970 and again in 1982 , there is only a 0.58 correlation in the ranking across the two years, and 28 states changed their

\footnotetext{
${ }^{17}$ Ideally, the fertility rate would be calculated as the ratio of births to the female population of child-bearing age. However, population estimates by state/sex/age group are not available between 1970 and 1980, so we use tolal population in our basic estimates. Altempting to correct our regressor for trends in the demographic composition of each state's population has litule effect on the results.

"Fertility fell dramatically as well from 1960-1965, and then was roughly constant until 1970. Data are not available for this earlier period. Our assumption is that cesarean utilization had adjusted to the earlier transition by 1970 , so that we can assess the net new contribution of the change from 1970 onwards. But the fact that the earlier fertility decline did not lead to widespread adoption of cesarean delivery highlights the crucial interactions between the incentives explored here and other factors determining technological adoption, such as the evolution of complementary technologies like fetal monitoring.
} 
ranking by more than 10 positions during this period.

What drove these differential fertility changes across the states? There are a number of hypotheses for the nationwide changes in fertility during this period, although we are aware of no state-specific analyses for these years: postponement of marriage and rising divorce rates; increasing use of reliable contraceptives; liberalized laws on abortion; 19 concern about environmental issues and overpopulation; increased entry into and opportunities in the labor force for women; and cyclical conditions. ${ }^{20}$ Gibson (1976) finds that over $80 x$ of the decline in fertility from $1970-75$ was due to declines in marital fertility. Both Gibson and Bloom and Trussell (1984) find that this decline was composed of both permanent fertility effects and changes in the timing of births; some of the "bounceback" in fertility in the later part of the decade may have been a result of these timing effects.

This paper will not explore the determinants of these cross-state fertility changes: rather, we will take them as exogenous local shocks to the income of ob/gyns which can be used to test the induced demand model. A number of alternative hypotheses can be suggested for a fertility/cesarean correlation, and we address these at length in Part IV. While it is difficult to convincingly refute all possible alternative hypotheses for this correlation, we find it to be remarkably robust to any alternative considered.

How large is the financial incentive arising from these differential fertility changes? We

\footnotetext{
1'Westoff and Ryder (1977) document a large decline in unwanted births during the 1960s, and conjecture that this continued into the 1970a. Statistics Canada (1984), in analyzing paralkel demographic trends in Canada, noted that in 1968, 16\% of couples in Quebec did not want their last child; by 1976, this ratio had declined to $7 \%$.

${ }^{20}$ Butz and Ward (1979) document countercyclical fertility, which they explain as a function of fertility responding to changing labor market opportunities of women. While there was a recession during the tail end of this period of fertility decline, the economy was growing at its start.
} 
noted above that one-half of $\alpha b / g y n$ income is from obstetrics, and fertility fell by $13.5 \%$ during the 1970-1982 period. Assuming that, in the absence of a behavioral response, the decline in income from obstetrics would parallel the decline in the birth rate, the implied fall in ob/gyn income of 6.75x, which is non-trivial. If the change in ob/gyn density is taken to be exogenous, then the pressure on $o b / g y n$ income is even greater: $o b / g y n s$ per birth rose by $58 \%$ in this era. Moreover, $\infty / g y n$ density increases could affect both income from obstetrics and gynecology, so that this represents a negative income shock on the order of $30 \%$ or more.

As Table 1 shows, the means for ob/gyn density and fertility support our hypothesis of induced demand: cesareans are more likely where there are more obstetricians and fewer births. ${ }^{21}$ However, this hypothesis is most appropriately tested in a multivariate regression framework, which we describe next.

\section{Empirical Framework}

In order to assess the effect of financial incentives on the cesarean decision, we initially run logit regressions of the form:

(5) $\operatorname{CSEC}_{i k}=f\left(\alpha+\beta_{1} X_{i k}+\beta_{2}\right.$ PREV $_{i k}+\beta_{3} Z_{k}+\beta_{4}$ LOBKID $\left._{k}+\beta_{3} \delta_{j}+\beta_{6} \tau_{1}+\epsilon_{24}\right)$

where $\operatorname{CSEC}_{i r}$ is equal to one if individual $i$ in hospital $h$ in state $j$ in year $t$ received a c-section, and zero otherwise

$\mathrm{X}$ is a set of individual demographic characteristics

PREV is an indicator for previous cesarean delivery

$Z$ is a set of hospital characteristics

LOBKID is the log of the number of ob/gyns per birth

$\delta$, is a full set of state dummy variables

$T_{1}$ is a full set of year dummy variables

In this regression, the cesarean decision is modelled as function of a number of characteristics

\footnotetext{
${ }^{21}$ Data on ob/gyn density in each state and year is from the AMA's Physician Characteristics and Distribution in the U.S.
} 
of the mocher and the hospital, as well as the ob/gyn density (ob/gyns per birth) in the state. If ob/gyn locational choice can be taken as exogenous, then the ob/gyn density provides the appropriate measure of the negative income shock for ob/gyns; cesareans are more likely to be induced where either the supply of ob/gyns are rising or the birth rate is falling. However, as documented above, we are concerned that the number of ob/gyns does not provide an exogenous measure of financial pressure, so that our preferred specification is:

(6) $\mathrm{CSEC}_{4 k}=\mathrm{f}\left(\alpha+\beta_{1} \mathrm{X}_{2 k}+\beta_{2} \mathrm{PREV}+\beta_{3} \mathrm{Z}_{4 k}+\beta_{4} \mathrm{LFERT}_{k}+\beta_{3} \delta_{j}+\beta_{6} \tau_{3}+\epsilon_{\text {ink }}\right)$

where LFERT is the log of the state/year fertility rate (births/100 population). In this specification, we identify the effect of financial pressure solely from changes in fertility. We normalize births by population because, since we are no longer explicitly including the number of ob/gyns in the state, population growth provides an exogenous indicator of the trend growth in ob/gyns (and thus the underlying growth in births needed to maintain ob/gyn income). ${ }^{22}$

We control for the age of the mother with a series of dummy variables, since the likelihood of cesarean delivery rises sharply with age; we include dummies for 5 year age intervals from 20-45, and for 45 and above (the omitted group being those under 20). We also include indicator variables for whether the mother is white or black (other non-white being the excluded group), and an indicator for married mothers.

We control for whether the mother is coded as having a previous cesarean, since cesarean

\footnotetext{
${ }^{2}$ Our conclusions are not sensitive to the use of this normalization. Appendix Table Al presents the basic regression results using log births, $\log$ births along with $\log$ population, $\log$ fertility, and the level of fertility. In each case, the coefficient on the regressor of interest is highly significant in the expected direction, although the magnitudes of the effects vary somewhat across the columns. When log birth and log population are entered separately, they have almost identical and opposite (statistically significant) coefficients, supporting the contention that a normalization by population is appropriate.
} 
delivery is almost certain in this case. ${ }^{25}$ In some specifications, we aiso control for several indicators of birth severity, in order to capture any spurious correlation between fertility rates and severity. The measures that we use are: breech presentation, fetal distress, maternal distress, and other complications. There are two problems, from our perspective, in including these controls. The first is that, since they are coded by the ob/gyn, they are also potentially endogenous to the same economic factors determining the cesarean decision. If physicians are going to induce demand for a cesarean, they must indicate a diagnosis which justifies the use of this more intensive technique. Numerous studies have documented such "coding creep" within the context of Medicare's Prospective Payment System (ie. Canter, Newhouse, and Relles, 1990). Second, there was 2 major change in the diagnosis coding system in the middie of our sample period (1978). The time series for some of the severity indicators show marked changes between 1978 and 1979 . So long as these changes are accurring nationwide, however, they will be captured by our time controls. Neither of these problems are likely to be important for the previous cesarean indicator.

Tabie 1 indicated that cesareans are more likely in larger hospitals, so we control for hospital bed size; we also control for whether the hospital is for-profit or government owned (non-profit being the excluded group). ${ }^{24}$ We include a full set of year dummies in all regressions, since there was a strong trend in cesarean delivery over this period. Finally, we include a full set of state dummies, so that we can control for fixed differences across areas which might be correlated with

\footnotetext{
${ }^{2}$ In our sample, $97 \%$ of women with previous cesarean childbirth had their births by cesarean delivery. The previous indicator may also be capturing some effects of birth order, since previous is zero by definition for the first birth, and first births are more likely to be delivered by cesarean section (Marieskind, 1979).

${ }^{24}$ Unfortunately data on teaching status of the hospital is not available, athough there is likely to be little within-state change in teaching status over this period that is not captured by changes in hospital size or ownership.
} 
both fertility and the cesarean decision.

\section{Part IV: Results}

\section{Basic Resules}

Table 2 presents the basic regression results. The first column reports the results from running equation (S). There is a significant positive relationship between the log of ob/gyn density and the probability of cesarean delivery: a 10 percent incresse in the ob/gyn density raises the probability of a cesarean by 0.6 percentage points.

The likelihood of cesarean delivery rises with age, as indicated by Table 1 . The increase is monotonic until the highest age group, where there is some reduction; however, this category contains only a very small number of observations, and an overall increase with age cannot be rejected. Cesarean delivery is more likely for married mothers and white mothers. Previous cesarean delivery, as expected, is an incredibly strong predictor of current cesarean delivery. Cesarean delivery is much more likely in large hospitals, a relation which has been documented at length in the literature. Cesareans are also somewhat more likely at for-profit hospitals, and much less likely at government hospitals, than at non-profit hospitals. The state and year dummies (not reported) are highly jointly significant.

In column (2), we disaggregate the doctor/birth ratio into the log of ob/gyns per 100 population and the $\log$ of the fertility race. Both coefficients are supportive of the induced demand view; that is, cesarean rates were rising both where the number of ob/gyns was increasing and where the birth rate was declining. Both coefficients are statistically significant. In column (3) we exclude the ob/gyn ratio altogether. The effect of fertility is somewhat strengthened; a fall in the fertility rate of $10 \%$ is associated with an increase in the likelihood of cesarean delivery of 0.97 percentage 
points. In column (4), we exclude the fertility rate, and examine the effect of changes in ob/gyns per 100 population. The effect of ob/gyn density increases somewhat.

How large are these effects? A $10 \%$ decline in the fertility rate approximately translates to $25 \%$ drop in the income of ob/gyns, if they do not change their behavior. In 1989 cesarean delivery was reimbursed $\$ 561$ more highly than normal childbirth, and the typical physician performs 168 birchs per year (AMA, 1993). A one percentage point rise in cesarean utilization translates to 1.68 more cesarean deliveries per year, or an income increase of 5943 . In 1989, the average ob/gyn income was $\$ 194,300$ (Medical Economics, September 3, 1990), so that this represents an income rise of only $0.5 \%$. This suggests that the shift to cesarean delivery only offset a very small part of the negative income shock facing ob/gyns. ${ }^{25}$

An alternative means of scaling the result is to calculate the implied contribution of the 1970 1982 fertility decline to the growth in cesarean utilization over this period. Viewing ob/gyn density as exogenous, our finding in column (1) implies that the increase in ob/gyn density over the 1970 1980 period can explain 2.9 percentage points of the 9.1 percentage point increase in primary cesarean delivery rates (32\%). ${ }^{26}$ Alternatively, viewing only the fertility differences as exogenous, we find that fall in fertility experienced by the U.S. from 1970-1982 can account for 1.45 percentage points of primary cesarean increase, which is only $16 \%$ of the growth rate of cesarean delivery over

\footnotetext{
${ }^{2}$ Unfortunstely, data does not exist to permit a comparable calculation for the 1970 s, but the inference is undoubtably quite similar in that era, given that Marieskind (1979) reports similar cesarean delivery fee premiums for the late 1970s (as noted above).

${ }^{25}$ In this calculation and the ones to follow, we compare the estimated effect of our inducement indicators to the growth in primary cesarean deliveries, not total cesarean deliveries. This is because, by conditioning on previous cesarean delivery, we are modelling the effect of inducement on the primary cesarean decision. In fact, if these models are estimated only on the sample without previous cesarean delivery, the results are aimost identical, as would be expected given the very small likelihood of vaginal birth after cesarean.
} 
this period.

To summarize, our basic findings are very supportive of the hypothesis that ob/gyns responded to falling fertility in this era by performing more cesarean section deliveries. The estimated response is small, however, relative to the shock to ob/gyn income, and the finding implies that the general fertility decrease during this era can explain only a small part of the overall growth in cesarean utilization.

\section{Specificarion Checks}

We find the results in Table 2 to be striking evidence for inducement. It is important to note, however, that there are a number of alternative interpretations of this finding than the one we have given. We are unable to refute all of these alternatives. In this section, we consider several of the most natural ones.

The first is that the average riskiness of births increases as the number of births decline. In this case, the use of cesarean delivery may change, not due to physician financial incentives, but due to the natural correlation between high-risk births and the use of c-sections. ${ }^{n}$ Micro-data studies have shown that very low or high birthweight or gestation are correlated with the use of cesarean delivery (Marieskind, 1979).

We have already controlled for some characteristics of the mother (ie. age) which might indicate a high risk birth. In Table 3, we consider two further steps; in each case, we only report

\footnotetext{
${ }^{n}$ For example, suppose that there are two types of mothers: those who are both careful with contraception and take good care of their fetuses ("prudent" mothers), and those who do neither ("imprudent" mothers). Fertility among imprudent mothers in this model will be roughly constant, so that, as fertility drops, a higher fraction of births will be represented by imprudent mothers. This will lead to a positive correlation between the fertility rate and the quality of the fetus, and thereby a spurious (from our perspective) negative correlation between the fertility rate and the cesarean section rate.
} 
the coefficients of interest, as the other covariates see little change in their marginal effects. In the first column, we control for three indicators of the underlying riskiness of births in state $j$ in year t: the fraction of live births that die within 28 days (the neonatal mortality rate), the fraction of births that are low birth weight at birth (less than $2500 \mathrm{grams}$ ), and the fraction of births that are very high birchweight at birth (more than $4500 \mathrm{grams}$ ). These data are reported by state and year in the publication Vital Statistics. If changes in fertility affect the use of cesarean delivery only through changes in birth severity, then including these regressors should substantially reduce our coefficient of interest.

In fact, the inclusion of these state level severity controls has little effect on our result. The coefficient on fertility is virtually unchanged. The results indicate that both more low and high birthweight births lead to more cesarean deliveries, which is consistent with our priors. Interestingly, there is a negative correlation between neonatal mortality and the cesarean rate. This could refute the hypothesis that more high risk births lead to more cesarean delivery. Alternatively, it could provide evidence that cesarean delivery itself lowers the neonatal mortality rate, despite the lack of convincing previous evidence described above. In the absence of a convincing instrument for cesarean delivery, however, we are reluctant to assign such a causal inference.

An alternative approach to controlling for underlying riskiness is to include diagnosis indicators for the severity of the individual birth. While these are potentially endogenous, it may still be instructive to examise the effects of their inclusion on our findings. In fact, as column (2) of Table 3 shows, our finding is somewhat strengthened when these controls are added. This further mitigates against an explanation for these results based on underlying riskiness. The severity indicators themselves are all highly significant. Conditional upon individual severity, the effects of state level severity measures are weakened; the only significant remaining correlation is with high 
birthweight births, and the coefficient on mortality is now positive.

In the remaining columns of Table 3, we directly examine the relationship between two of these severity indicators and the fertility rate. There is a significant rise in the rate at which both fetal distress and maternal distress are diagnosed as fertility decreases. This could be construed as evidence that fertility affects the underlying riskiness of the birth. Alternatively, it could be evidence that financial incentives affected physician coding decisions; increased use of cesarean delivery must be justified by increased coded severity. This would be consistent with past evidence from the Medicare PPS (Carter, Newhouse, and Relles, 1990). It is also consistent with the very rapid rise in documented birth severity over the 1970s, despite no obvious deterioration in this era in the health of pregnant women. In any case, even when we condition on individual severity in column (2), the inducement relationship remains.

A second alternative hypothesis is that the fertility effect is operating through correlations between birth order and cesarean delivery. A number of studies note that cesareans are more likely for first births, as well as births which are the fitth or higher (Marieskind, 1979; Placek and Taffel, 1980; Tussing and Wojotowycz, 1992). Furthermore, as fertility declines, a larger fraction of births will be first births, although a smaller fraction will be of a higher order. ${ }^{2 a}$ Thus, there is a potential for omitted variable bias from our not having birth order data.

We address this potential problem using state aggregate information on the distribution of births across birth order. In the final column of Table 3, we include, along with the state/year severity controls, state/year controls for the fraction of births of order 1 , and the fraction of order 5 or more. Including these variables has little effect on the results. The variables themselves are

\footnotetext{
${ }^{20}$ The effect on order 1 is much larger; summing the fraction of births that are of order 1 and order 5 or more, there is a strong negative correlation with fertility.
} 
insignificant. The result is similar if the individual level severity controls are included as well.

A third alternative is that our findings are not the result of a robust correlation, but rather are driven by the experience of one or two outlying states. Nternatively, our findings may simply reflect the experience of one outlying region where fertility was falling and taste for cesareans was rising. In results not reported, we have tried both excluding from our sample the five states with the largest fertility fall and the five states with the largest fertility rise over the 1970-1982 period, and allowing each of the four census regions to have its own specific time trend in fertility. In both cases, the cortelation between fertility and cesarean delivery was robust.

Finally, this finding could be a function of changing insurance coverage of mothers. Unfortunately, we have been unable to control for source of payment in the regressions thus far because it is missing before 1977. As noted above, cesarean delivery is more likely for insured mothers, and Leibowitz (1990) shows that births are likely to be moved forward if insurance coverage becomes more generous. This evidence suggests that any bias from omitted insurance status measures is going against our finding of a negative correlation between fertility and cesarean delivery. Nevertheless, we can use the data on payer source for the period from 1977 onwards to examine the effect of omitting insurance type from our regression.

In the first column of Table 4, we present our regression results for the 1977 to 1982 period

\footnotetext{
A related economic omitted variable is the labor force participation of the mothers in our sample. Female labor force participation was also increasing dramatically during the period under saudy. Increased labor force participation is likely to be correlated with reduced, or delayed, fertility (Olsen, 1994). The correlation between labor force participation and the desire for cesarean is unclear: on the one hand, cesarean delivery offers increased predictability in the timing of delivery; on the other hand, the recovery times for cesareans are generally longer than for normal childbirth. We do not have information on labor force attachment for our sample, and there is not even data available for the 1970s on female labor force participation rates by state/year. As a proxy, we have tried in earlier work controlling for the state unemployment rate and state average income. This had no effect on our relationship of interest.
} 
only. The relationship of interest is robust to this sample period restriction; the coefficient is almost identical to that in Table 2, and is statistically significant. In the next column we include dummy variables for being privately insured or being uninsured. These variables have their expected signs, but the control for being uninsured is small and insignificant. There is little effect on the coefficient of interest, suggesting no bias from omittod insurance status variables.

The surprising finding of an equal rate for publicly insured (the excluded group) and uninsured patients may be a function of omitted characteristics correlated with payer stanus. A large literature documents the fact that the uninsured are in worse health along a number of dimensions (ie. Kasper, 1986), which would bias them towards having more cesarean deliveries conditional on financial incentives. In column (3) of Table 4, we control for individual severity using the measures listed in Table 3. Doing so substantially reduces the coefficient on private pay and raises (in absolute value) the coefficient on uninsured, although the latter remains insignificant.

The data on payer source allow a further test of our hypothesis. If physicians are inducing cesarean delivery for financial purposes, then this response should be greatest among those with the most generous insurance coverage, and smallest for those with the least generous. That is, for uninsured parients who can be expected to only pay a small portion of their bill, there is little expected reward to performing a cesarean relative to a normal childbirth. For privately insured patients, where the fee differential is greatest, the rewards will be the greatest as well. Therefore, if financial incentives are driving the fertility/cesarean relationship, we should see that this relationship is strongest for those with private insurance and weakest for the uninsured.

We demonstrate that this is the case in the remaining columns of Table 4. We do so by augmenting our basic regression framework with interactions between payer status and the fertility rate. As we show in column (4), the private payer interaction is negative, indicating that fertility 
falls had their greatest impact on this population, and the uninsured interaction is positive, indicating the smallest impact of fertility changes on this group. That is, for the privately insured, the net effect of a $10 \%$ drop in fertility is 2 rise in the cesarean rate of 1.15 percentage points; but for the uninsured, the net effect is a rise in the cesarean rate of only 0.65 percentage points. Neither interaction is significant, however, perhaps due to the collinearity in the insurance measures. In the next two columns, we therefore include these interactions separately, and they achieve significance in each case.

In the final three columns, we repext this exercise including the severity controls. The story is similar; the findings are stronger, albeit less precisely estimated. ${ }^{30}$ In fact, in this case we estimate that a $10 \%$ fall in fertility ted to a rise in the cesarean rate for the privately insured of 1.1 percentage points, but a rise for the uninsured of only 0.27 percentage points. Thus, overall, the results are supportive of our contention that the fertility coefficient measures a response to financial incentive incentives; fertility falls induced cesarean increases in the very groups where the financial incentives were strongest.

\section{Part V: Is There an Asymmetric Response to Fertility Changes?}

In the initial interpretation of our results, we applied the coefficient on fertility to its 19701982 trend in order to assess the contribution of ferility declines to the growth of cesarean delivery. However, such an interpretation is only appropriate if the use of cesarean delivery reacts symmetrically to increases and decreases in the fertility rate. In fact, there is reason to suspect an asymmetric response of cesarean delivery to inducement incentives. Even if ob/gyns would like to

\footnotetext{
${ }^{30}$ The coefficients on the main effects (private pay and uninsured coefficients) are actually wrons signed, in columns (4)-(9), but at the mean fertility rate the partial derivatives are correctly signed when the severity controls are included.
} 
switch back to normal delivery, it may be difficult to do so once cesarean delivery has become an accepted mode of delivery for a given type of birth. The most likely explanation for such an asymmetry would be the evolution of malpractice rules, which use local standards of care in deciding whether treatment was appropriate. If cesarean delivery had evolved to be the standard of care for that type of birth, then this built-in irreversibility of malpractice standards will make it difficult to revert to vaginal childbirth." More generally, a model with evolving practice "norms" could also yield a similar prediction of technological "stickiness".

If technological diffusion is "sticky", it has important implications for the evaluation of economic incentives; such hysteresis suggests potential long run effects of short run economic changes. It may also imply asymmetric responses to declines and increases in fertility, with the declining fertility of the early 1970s leading to differential adoption of cesarean delivery across areas. but the subsequent increase having no effect. Indeed, the time series evidence would suggest that this is the case, as cesarean delivery continued to grow after 1976 despite a rise in the fertility rate. The time series evidence, however, does not prove that there is an asymmetric response, because our analysis controls for general time effects in considering the effect of differential state fertility changes.

In this section, therefore, we test for an asymmetric response of the use of cesarean delivery to rising and falling fertility rates. We do so by creating for each state two subperiods: a "falling" period, and a "non-falling" period. Nationally, these periods would be represented by 1970-1975, and 1975-1982 respectively; for North Carolina, 1970-1976 and 1976-1982; for Kansas, 1970-1973 and 1973-1982 (refer to Figures 2-3b). One potentially problematic issue is how to treat the "turning

\footnotetext{
"Of course, if the irreversibility was symmetric, then practice patterns would never change. But there may be a systematic bias in evolving standards of care towards the newest standard, at the cost of possible reversibility to the old standard.
} 
point" year, in which the rapid decline ended and (for most states) a gradual rise began (ie. 1976 for North Carolina). In the analysis below, we try three different approaches: including this year in the -falling" period, including it in the "non-falling" period, and dropping it altogether.

We run regressions of the form:

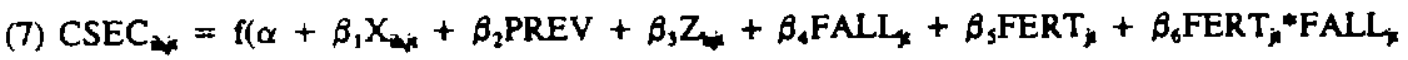

$$
\left.+\beta_{6} \delta_{j}+\beta_{7} \pi_{1}+\epsilon_{3 i n}\right)
$$

where FALL $L_{x}$ is a dummy which is equal to one if state $j$ is in the "falling" sample in year $t$, and 0 otherwise. In this framework. $B_{6}$ measures the differential effect of fertility on cesarean delivery in the period where fertility is falling. If there is a symmetric response to falling and rising fertility, then $\beta_{5}$ shouid be equal to the previous estimates for the fertility effect, and $\beta_{6}$ should be equal to zero. There is some heterogeneity in the timing of the turning points across states: 21 states have their turning points in 1976, 7 in 1975, 3 in 1974, 17 in 1973, and 1 in 1972.

The results of estimating this equation are presented in Table 5, for the three different treatments of the turning point year. In no case is there evidence of an asymmetric response. The response to fertility is equally strong in the period where fertility is rising and falling. This suggests that, at the margin, physicians are able to both increase and decrease intensity in response to financial incentives.

\section{Part VI: Conclusions}

Rising medical costs have been a primary impetus for health care reform in the U.S. Yet, despite the concern of public policy-makers over this phenomenon, the causes of these cost increases are not well understood. Atuempts to account for this increase in costs by factors such as the aging of the population, increased income, and the growth in insurance coverage leave well over half of 
the cost rise unexplained (Newhouse, 1992). This residual is often attributed to the diffusion of costly new medical technologies (Newhouse, 1992; Weisbrod, 1991), and recent theoretical work (Goddeeris, 1984; Baumgardner, 1991) has even suggested that such technological advance in medicine may be welfare reducing. A key question for evaluating these models is whether physician financial incentives play any role in the adoption of new medical procedures.

We have investigated the role of physician financial incentives in the substitution of cesarean childbirth for normal delivery in the 1970-1982 period. Cesarean delivery is fairly inexpensive relative to other "replacement" medical technologies. Yet, its very rapid adoption despite a lack of convincing evidence that it leads to improvements in birth outcomes raises the possibility that this was not simply the case of a higher quality technique replacing an inferior one. Our results suggest that, in fact, physician financial incentives did play a significant role in the substitution towards cesarean childbirth. However, this role was a small one relative to other factors explaining the rapid growth in cesarean utilization.

This work can be usefully extended in at least three directions. First, similar tests could be carried out for the adoption of other medical technologies in different time periods. This would be particularly useful for cases of very expensive replacement technologies with litale convincing evidence of improved outcomes. Second, our paper leaves largely unanswered the question of why cesarean delivery, which could be done fairly successfully from the start of the 20 th century onwards (Marieskind, 1979), spread so rapidly after 1970. Finally, there is a general sense in the medical literature that the level of cesarean delivery is "100 high" (NIH, 1981). Such a conclusion can only be drawn after weighing more carefully the costs and benefits of this procedure. While there is considerable evidence on the physiological and financial costs of cesarean delivery, there is little convincing evidence on its benefits. Assessing these benefits should be a high priority for future 
research. 


\section{References}

American Colkge of Obstetricians and Gynecologists (1989). "Medicaid Reimbursement for Obstetric Care (Specialist) by State". Washington, D.C.: ACOG.

American College of Obstetricians and Gynecologists (1992). "The Economics of Ob/Gyn Practice in the United States, 1990-91", Economic Impact. ACOG: Department of Health Economics Analysis.

American Medical Association (1993). Physician Markesplace Statistics. Chicago: AMA.

Auster, Richard D. and Oaxaca, Ronald L. (1981) "Identification of Supplier Induced Demand in the Health Care Sector," Journal of Human Resowrces, 337-342.

Baumgardner, James (1991). "The Interaction Berween Forms of Insurance Contract and Types of Technical Change in Medical Care," RAND Jowrnal of Economics, 22, 36-53.

Becker, Gary (1992). A Treatise on the Family. Cambridge: Harvard University Press.

Birch, Stephen (1988). "The Identification of Supplier-Inducement in a Fixed Price System of Health Care Provision: The Case of Denstistry in the United Kingdom," Jownal of Health Economics, 7, 129-150.

Bloom, David E., and James Trussell (1984). "What are the Determinants of Delayed Childbearing and Permanent Childlessness in the United States?," Demography, 21, 591-611.

Butz, Michael P. and Ward, Michael P. (1979). "The Emergence of Countercyclical U.S. Fertility," American Economic Review, 69, 318-328.

Carter, G.M, J.P. Newhouse, and D.A. Relles (1990). "How Much Change in the Case Mix Index is DRG Creep," Jownal of Health Economics, 9, 411-428.

Cromwell, Jerry and Mitchell, Janet B. (1986) "Physician-Induced Demand for Surgery," Journal of Health Economics S, 293-313.

Dranove, David. (1988) "Demand Inducement and the Physician/Patient Relationship," Economic Inquiry, 281-298.

Dranove, David, and Paul Wehner (1994). 'Physician Induced Demand for Childbirths," Jownal of Health Economics, 13:61-75.

Epstein, Aronld M. and Joel Weissman (1989). "Characteristics of Patients who Contribute to Hospital Free Care and Bad Debt Write-Off". Mimeo, Harvard School of Public Health.

Evans, Robert A. (1974). "Suppplier-Induced Demand: Some Empirical Evidence and 
Implications," in The Economics of Health and Medical Care, Mark Perlman, ed., London: MacMillan.

Feldman, Roger. (1988) "Competition Among Physicians, Revisited," Journal of Health Politics, Policy and Low, vol. 13. no 2., 239-261.

Feldman, Roger, and Frank Sloan (1989) "Reply from Feldman and Sloan," Journal of Health Politics, Policy and Law, vol 14., no.3. , 621-625.

Finkler, Merton D., and David D. Wirschafter (1993). 'Why Pay Extra for Cesarean-Section Deliveries?," Inquiry, 30, 208-215.

Freeman, Richard (1976). The Overeducated American. New York: Academic Press.

Fuchs, Victor. (1978). "The Supply of Surgeons and the Demand for Operations," Journal of Human Resources, XIII, Supplement.

Gibson, Campbell (1976). "The U.S. Fertility Decline, 1961-1975: The Contribution of Changes in Marital Status and Marital Fertility," Fanily Planning Perspectives, 8, 249-256.

Gooderis, John (1984). 'Medical Insurance, Technological Change, and Welfare,'Economic Inquiry, 22, 56-67.

Graves, E. J., and L.J. Kozack (1992). "National Hospital Discharge Survey: Annual Summary, 1989," Vital Health Statistics, 13, 109-120.

Gruber, Jonathan (1992). "The Efficiency of a Group-Specific Mandated Benefit: Evidence from Health Insurance Benefits for Maternity". NBER Working Paper "4157.

Grytten, Jostein, Dorthe Holst, and Petter Laake (1990). "Supplier Inducement: Its Effect on Dental Services in Norway," Journal of Health Economics, 9, 483-491.

Health Insurance Association of America (1989) "The Cost of Maternity Care and Childbirth in the United States, 1989*. Research Bulletin of the Healch Insurance Association of America.

Hurley, Jeremiah, Labelle, Roberta, and Rice, Thomas. (1990) "The Relationship Berween Fhysician Fees and the Utilization of Medical Services in Ontario," Advances in Health Economics and Health Services Research, vol. 11, 49-78.

Kasper, Judith D. (1986). "Health Status and Utilization: Differences by Medicaid Coverage and Income," Health Care Financing Review, 7(4), 1-17

Keeter, Emmett B., and Mollyann Brodie (1993). "Economic incentives in the Choice Between Vaginal Delivery and Cesarean Section," The Milbank Quarterly, 71, 365-404. 
Leibowitz, Arleen (1990). "The Response of Births to Changes in Health Care Costs," Journal of Human Resources, 25:697-711.

Localio, A. Russell, et. al. (1993) 'Relationship Between Malpractice Claims and Cesarean Delivery," Journal of the American Medical Association, vol 269, no. 3, 366-373.

Marieskind, Helen I. (1979) "An Evaluation of Caesarean Section in the Unitod States" Final Report Submitted to the Department of Health, Education and Welfare Office of the Assistant Secretary for Planning and Evaluation/Health.

McGuire, Thomas G. and Pauly, Mark V. (1991) 'Physician response to fee changes with multiple payers," Journal of Healeh Economics, 10, 385-410.

National Institutes of Health (1981). Cesarean Childbirth. Washington, D.C.: U.S. Department of Health and Human Services

Newhouse, Joseph (1970). 'A Model of Physician Pricing," Southern Economic Journal, 37, 174 183.

Newhouse, Joseph (1992). "Medical Care Costs: How Much Welfare Loss?," Journal of Economic Perspectives, 6, 3-21.

Phelps, Charles. E. (1986). "Induced Demand--Can We Ever Know its Extent?"' Journal of Health Economics 5, 355-365.

Placek, Paul J., Taffel, Selma M. (1980). "Trends in Cesarean Section Rates for the Unitod States, 1970-1978," Public Health Reports. 540-548.

Rice, Thomas (1984). 'Physician-Induced Demand for Medical Care: New Evidence from the Medicare Program," Advances in Health Economics and Healh Services Research, vol 6, 129-160.

Rice, Thomas H. and Labelle, Roberta J. (1989). "Do Physicians Induce Demand for Medical Services?." Journal of Healeh Politics, Pollicy and Law, vol 14, no. 3.

Shiono, Parricia H., McNellis, Donald, and George G. Rhoads (1987). "Reasons for the Rising Cesarean Delivery Rates, 1978-1984," Obstetrics \& Gynecology. 696-700.

Stafford, Randall S. (1990). "Cesarean Section Use and Source of Payment: An Analysis of Califomia Hospital Discharge Abstracts," American Journal of Public Health, 313-315.

Statistics Canada (1984). Fertiliry in Canada: From Baby-Boom to Baby-Bust. Ottawa: Minister of Supply and Services.

Tussing, Date A., and Wojotowycz, Martha A. (1992). "The Cesarean Decision in New York State, 
1986,' Medical Care, 529-540.

Wodig, Gerard, Mitchell Janet B., Cromwell, Jerry (1989). 'Can Price Controls Induce Optimal Physician Behavior?" Joumal of Health Politics, Policy and Law, vol. 14, no. 3. 601-619.

Weisbrod, Burt (1991). "The Health Care Quadrilemma: An Essay on Technological Change, Insurance, Quality of Care, and Cost Concainment," Joumal of Economic Literature, XXIX, 523-552.

Westoff, Charles F., and Norman B. Ryder (1977). The Consraceprive Rewolution. Princeton, N.J.: Princeton University Press.

Williams, Ronald and Hawes, Warren (1979). "Cesarean Section, Fetal Monitoring, and Perinatal Mortality in California," American Joumal of Public Health, vol. 69, no. 9, 864-870.

Yip, Winnie (1994). "Physician Responses to Medicare Fee Reductions: Changes in the Volume and Intensity of Supply of Coronary Artery Bypass Graft (CABG) Surgery in the Medicare and Private Sectors". Mimeo, MIT. 


\begin{tabular}{|c|c|c|c|}
\hline & All Birthe & No C-Section & C-Soction \\
\hline Ceanrean Delivery & 0.119 & 0 & 1 \\
\hline$A_{80}<20$ & 0.177 & 0.183 & 0.134 \\
\hline$A g=20-25$ & 0.341 & 0.346 & 0.308 \\
\hline Ase $25-30$ & 0.296 & 0.293 & 0.321 \\
\hline Age $30-35$ & 0.132 & $0.12 B$ & 0.165 \\
\hline Ase $35-40$ & 0.041 & 0.039 & 0.055 \\
\hline Age $40-45$ & 0.010 & 0.009 & 0.014 \\
\hline Age 45 + & 0.002 & 0.002 & 0.003 \\
\hline Married & 0.793 & 0.792 & 0.798 \\
\hline While & 0.693 & 0.692 & 0.698 \\
\hline Bleck & 0.163 & 0.163 & 0.167 \\
\hline Number of Bods & $\begin{array}{l}360.5 \\
{[301.2]}\end{array}$ & $\begin{array}{l}356.8 \\
{[302.5]}\end{array}$ & $\begin{array}{c}388.2 \\
{[389.4]}\end{array}$ \\
\hline For-Profit & 0.035 & 0.035 & 0.041 \\
\hline Government & 0.261 & 0.264 & 0.237 \\
\hline Previous Cesarean & 0.035 & 0.001 & 0.286 \\
\hline Breoch Presenzation & 0.028 & 0.017 & 0.107 \\
\hline Fetal Distresa & 0.045 & 0.015 & 0.272 \\
\hline Maternal Distresas & 0.022 & 0.014 & 0.083 \\
\hline Other Complications & 0.329 & 0.305 & 0.509 \\
\hline Ob/Gyne por 100 birthe & $\begin{array}{c}0.621 \\
{[0.248]}\end{array}$ & $\begin{array}{c}0.614 \\
{[0.246]}\end{array}$ & $\begin{array}{c}0.671 \\
{[0.261]}\end{array}$ \\
\hline $\begin{array}{l}\text { Ob/Gys por } 100 \text { population } \\
\left(+10^{2}\right)\end{array}$ & $\begin{array}{c}0.954 \\
{[0.304]}\end{array}$ & $\begin{array}{c}0.946 \\
{[0.301]}\end{array}$ & $\begin{array}{c}1.020 \\
{[0.319]}\end{array}$ \\
\hline Birthe per 100 population & $\begin{array}{c}1.59 \\
{[0.23]}\end{array}$ & $\begin{array}{l}1.60 \\
{[0.24]}\end{array}$ & $\begin{array}{c}1.57 \\
{[0.23]}\end{array}$ \\
\hline Number of Obeervations & 255593 & 225202 & 30391 \\
\hline
\end{tabular}

Notes: Dats from NHDS detuset and other sources deacribed in text. 
Table 2: Bacic Regreasion Recults

Depeodeat Variable is a Dummy for Cesarean Delivery

\begin{tabular}{|c|c|c|c|c|}
\hline & (1) & (2) & (3) & (4) \\
\hline Log Ob/Gyn per 100 birthe & $\begin{array}{c}0.578 \\
(0.126)\end{array}$ & & & \\
\hline $\begin{array}{c}\text { Log Fertility } \\
\text { (Birthe per } 100 \text { population) }\end{array}$ & & $\begin{array}{c}-0.888 \\
(0.202)\end{array}$ & $\begin{array}{c}-0.923 \\
(0.201)\end{array}$ & \\
\hline $\begin{array}{l}\text { Log Ob/Gyn per } \\
100 \text { population }\end{array}$ & & $\begin{array}{c}0.342 \\
(0.174)\end{array}$ & & $\begin{array}{c}0.410 \\
(0.174)\end{array}$ \\
\hline Age $20-25$ & $\begin{array}{c}0.001 \\
(0.022)\end{array}$ & $\begin{array}{c}0.001 \\
(0.022)\end{array}$ & $\begin{array}{c}0.001 \\
(0.022)\end{array}$ & $\begin{array}{c}0.001 \\
(0.022)\end{array}$ \\
\hline Age $25-30$ & $\begin{array}{c}0.081 \\
(0.023)\end{array}$ & $\begin{array}{c}0.081 \\
(0.023)\end{array}$ & $\begin{array}{c}0.082 \\
(0.023)\end{array}$ & $\begin{array}{c}0.082 \\
(0.023)\end{array}$ \\
\hline Age $30-35$ & $\begin{array}{c}0.153 \\
(0.027)\end{array}$ & $\begin{array}{c}0.153 \\
(0.027)\end{array}$ & $\begin{array}{c}0.153 \\
(0.027)\end{array}$ & $\begin{array}{c}0.154 \\
(0.027)\end{array}$ \\
\hline Age $35-40$ & $\begin{array}{c}0.419 \\
(0.037)\end{array}$ & $\begin{array}{c}0.418 \\
(0.037)\end{array}$ & $\begin{array}{c}0.418 \\
(0.037)\end{array}$ & $\begin{array}{c}0.419 \\
(0.037)\end{array}$ \\
\hline Age $40-45$ & $\begin{array}{c}0.616 \\
(0.065)\end{array}$ & $\begin{array}{c}0.616 \\
(0.065)\end{array}$ & $\begin{array}{c}0.616 \\
(0.064)\end{array}$ & $\begin{array}{c}0.615 \\
(0.064)\end{array}$ \\
\hline Age $45+$ & $\begin{array}{c}0.341 \\
(0.143)\end{array}$ & $\begin{array}{c}0.341 \\
(0.143)\end{array}$ & $\begin{array}{c}0.342 \\
(0.143)\end{array}$ & $\begin{array}{c}0.342 \\
(0.143)\end{array}$ \\
\hline Married & $\begin{array}{c}0.018 \\
(0.020)\end{array}$ & $\begin{array}{c}0.019 \\
(0.020)\end{array}$ & $\begin{array}{c}0.019 \\
(0.020)\end{array}$ & $\begin{array}{c}0.018 \\
(0.020)\end{array}$ \\
\hline White & $\begin{array}{c}0.025 \\
(0.022)\end{array}$ & $\begin{array}{c}0.026 \\
(0.022)\end{array}$ & $\begin{array}{c}0.026 \\
(0.022)\end{array}$ & $\begin{array}{c}0.024 \\
(0.022)\end{array}$ \\
\hline Black & $\begin{array}{l}-0.003 \\
(0.030)\end{array}$ & $\begin{array}{c}-0.003 \\
(0.030)\end{array}$ & $\begin{array}{l}-0.003 \\
(0.030)\end{array}$ & $\begin{array}{c}-0.004 \\
(0.030)\end{array}$ \\
\hline Previous Cesarean & $\begin{array}{c}5.760 \\
(0.064)\end{array}$ & $\begin{array}{c}5.761 \\
(0.064)\end{array}$ & $\begin{array}{c}5.761 \\
(0.064)\end{array}$ & $\begin{array}{c}5.760 \\
(0.064)\end{array}$ \\
\hline $\begin{array}{l}\text { Number of Beds } \\
\qquad\left(/ 10_{1}\right)\end{array}$ & $\begin{array}{c}0.263 \\
(0.025)\end{array}$ & $\begin{array}{c}0.264 \\
(0.025)\end{array}$ & $\begin{array}{c}0.263 \\
(0.025)\end{array}$ & $\begin{array}{c}0.264 \\
(0.025)\end{array}$ \\
\hline For-Profit & $\begin{array}{c}0.091 \\
(0.039)\end{array}$ & $\begin{array}{c}0.092 \\
(0.039)\end{array}$ & $\begin{array}{c}0.094 \\
(0.039)\end{array}$ & $\begin{array}{c}0.093 \\
(0.039)\end{array}$ \\
\hline Goverameat & $\begin{array}{c}-0.197 \\
(0.020)\end{array}$ & $\begin{array}{c}-0.198 \\
(0.020)\end{array}$ & $\begin{array}{c}-0.198 \\
(0.020)\end{array}$ & $\begin{array}{l}-0.197 \\
(0.020)\end{array}$ \\
\hline
\end{tabular}

Notes: Standerd exrors in parenthesed. Regressions are nun as logits. All regressions include full set of ante and year dummies. $\mathrm{N}=255,593$. 
- Table 3: Specification Chocks - Birth Soverity

\begin{tabular}{|c|c|c|c|c|c|}
\hline Dependent Var. & $\begin{array}{c}\text { (1) } \\
\text { Cesarean }\end{array}$ & $\begin{array}{c}\text { (2) } \\
\text { Conaroan }\end{array}$ & $\begin{array}{c}\text { (3) } \\
\text { Fotal } \\
\text { Dietreas }\end{array}$ & $\begin{array}{c}\text { (4) } \\
\text { Misternal } \\
\text { Dititeas }\end{array}$ & $\begin{array}{c}\text { (5) } \\
\text { Ceasean }\end{array}$ \\
\hline Los Fertility & $\begin{array}{l}-0.934 \\
(0.205)\end{array}$ & $\begin{array}{l}-1.015 \\
(0.250)\end{array}$ & $\begin{array}{l}-0.695 \\
(0.274)\end{array}$ & $\begin{array}{l}-0.951 \\
(0.347)\end{array}$ & $\begin{array}{l}-0.883 \\
(0.211)\end{array}$ \\
\hline $\begin{array}{l}\text { Neopatal } \\
\text { Mortality }\end{array}$ & $\begin{array}{l}-0.018 \\
(0.012)\end{array}$ & $\begin{array}{c}0.015 \\
(0.015)\end{array}$ & $\begin{array}{c}-0.031 \\
(0.016)\end{array}$ & $\begin{array}{r}0.022 \\
(0.023)\end{array}$ & $\begin{array}{l}-0.019 \\
(0.014)\end{array}$ \\
\hline $\begin{array}{l}\text { Low Birthweight } \\
\text { ( }<2500 \text { grams) }\end{array}$ & $\begin{array}{c}14.12 \\
(4.671)\end{array}$ & $\begin{array}{c}7.152 \\
(5.713)\end{array}$ & $\begin{array}{c}7.654 \\
(6.213)\end{array}$ & $\begin{array}{c}13.50 \\
(8.388)\end{array}$ & $\begin{array}{c}15.52 \\
(4.706)\end{array}$ \\
\hline $\begin{array}{l}\text { High Birthwoight } \\
\text { (> } 4200 \text { grems) }\end{array}$ & $\begin{array}{c}12.10 \\
(7.481)\end{array}$ & $\begin{array}{c}18.65 \\
(9.173)\end{array}$ & $\begin{array}{c}0.674 \\
(9.691)\end{array}$ & $\begin{array}{l}-3.131 \\
(13.48)\end{array}$ & $\begin{array}{c}12.32 \\
(7.505)\end{array}$ \\
\hline $\begin{array}{l}\text { Previous } \\
\text { Ceanrean }\end{array}$ & $\begin{array}{c}5.761 \\
(0.064)\end{array}$ & $\begin{array}{c}7.421 \\
(0.066)\end{array}$ & $\begin{array}{l}-0.483 \\
(0.060)\end{array}$ & $\begin{array}{l}-0.476 \\
(0.088)\end{array}$ & $\begin{array}{c}5.761 \\
(0.064)\end{array}$ \\
\hline $\begin{array}{c}\text { Breech } \\
\text { Preseotation }\end{array}$ & & $\begin{array}{c}2.951 \\
(0.032)\end{array}$ & & & \\
\hline Fetal Distreas & & $\begin{array}{c}4.368 \\
(0.028)\end{array}$ & & & \\
\hline $\begin{array}{l}\text { Maternal } \\
\text { Diatrese }\end{array}$ & & $\begin{array}{c}2.001 \\
(0.037)\end{array}$ & & & \\
\hline $\begin{array}{c}\text { Orber } \\
\text { Complications }\end{array}$ & & $\begin{array}{c}1.997 \\
(0.021)\end{array}$ & & & \\
\hline $\begin{array}{c}\text { Fraction 1st } \\
\text { Births }\end{array}$ & & & & & $\begin{array}{c}0.500 \\
(0.652)\end{array}$ \\
\hline $\begin{array}{l}\text { Fraction 5th or } \\
\text { More Births }\end{array}$ & & & & & $\begin{array}{r}-0.722 \\
(1.570)\end{array}$ \\
\hline
\end{tabular}

Notes: Standard errors in parentheacs. All regressions include at of regreseors preseoled in Table 2, aloog with full set of tate and year dummies. All regresaions nun as logits. $\mathrm{N}=255,593$. 


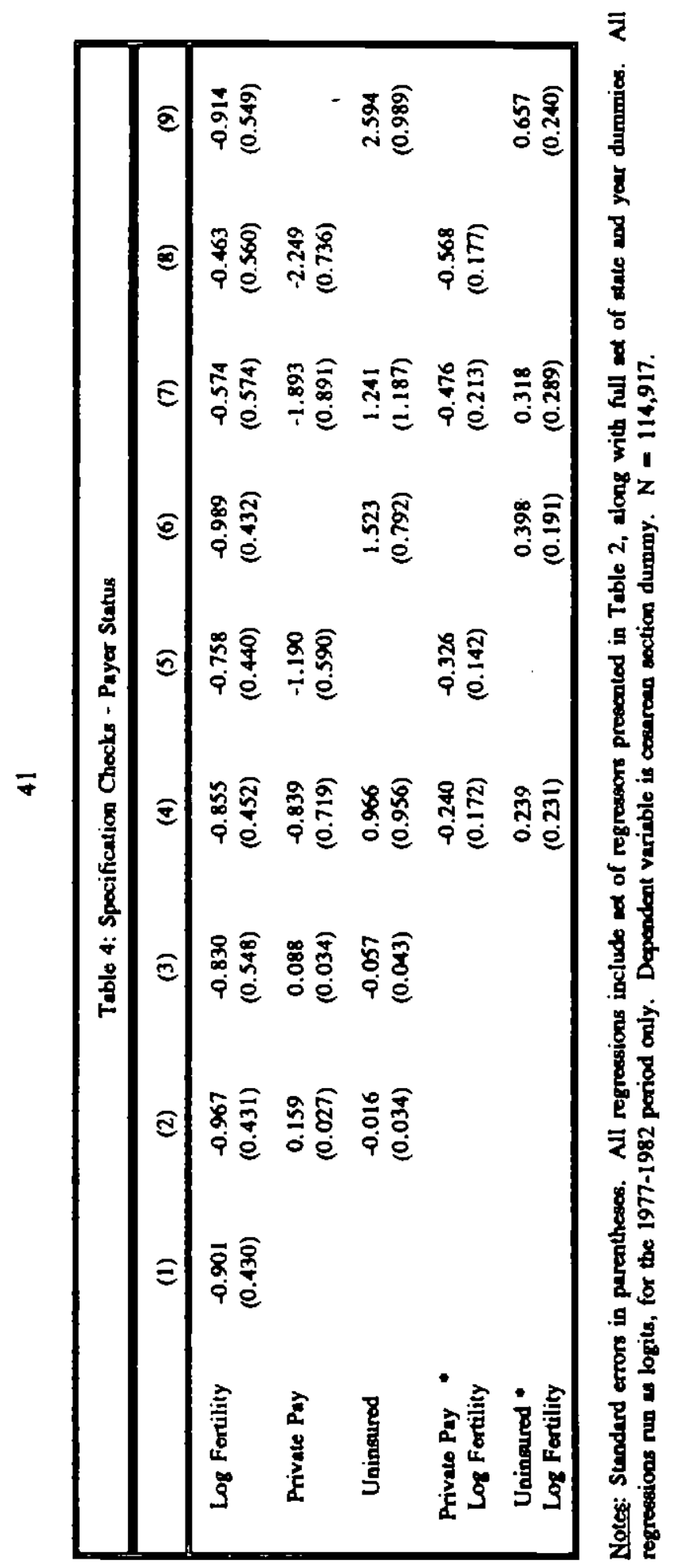


Table 5: Arymmetric Respone?

\begin{tabular}{|c|c|c|c|}
\hline $\begin{array}{c}\text { Treatmeat of Tursing } \\
\text { Point Year }\end{array}$ & $\begin{array}{c}\text { (1) } \\
\text { Include in Fall }\end{array}$ & $\begin{array}{c}\text { (2) } \\
\text { Include in Rise }\end{array}$ & $\begin{array}{c}\text { (3) } \\
\text { Drop }\end{array}$ \\
\hline Los Fertility & $\begin{array}{r}-0.929 \\
(0.202)\end{array}$ & $\begin{array}{r}-0.874 \\
(0.207)\end{array}$ & $\begin{array}{c}-0.881 \\
(0.212)\end{array}$ \\
\hline Falling? & $\begin{array}{r}0.234 \\
(0.580)\end{array}$ & $\begin{array}{r}-0.029 \\
(0.634)\end{array}$ & $\begin{array}{l}-0.005 \\
(0.650)\end{array}$ \\
\hline Fertility ${ }^{*}$ Fulling & $\begin{array}{c}0.055 \\
(0.137)\end{array}$ & $\begin{array}{c}0.002 \\
(0.150)\end{array}$ & $\begin{array}{c}0.003 \\
(0.153)\end{array}$ \\
\hline Number of Obe & 255,593 & 255,593 & 236,950 \\
\hline
\end{tabular}

Notes: Standind errors in pareatbeses. All regreations include wet of regreasors presented in Table 2, along with full set of atale and year dummies. All regressions nun as logite. Dependent varisble is cesarean section dummy. Regreasion epecification is equation (7) in text. 


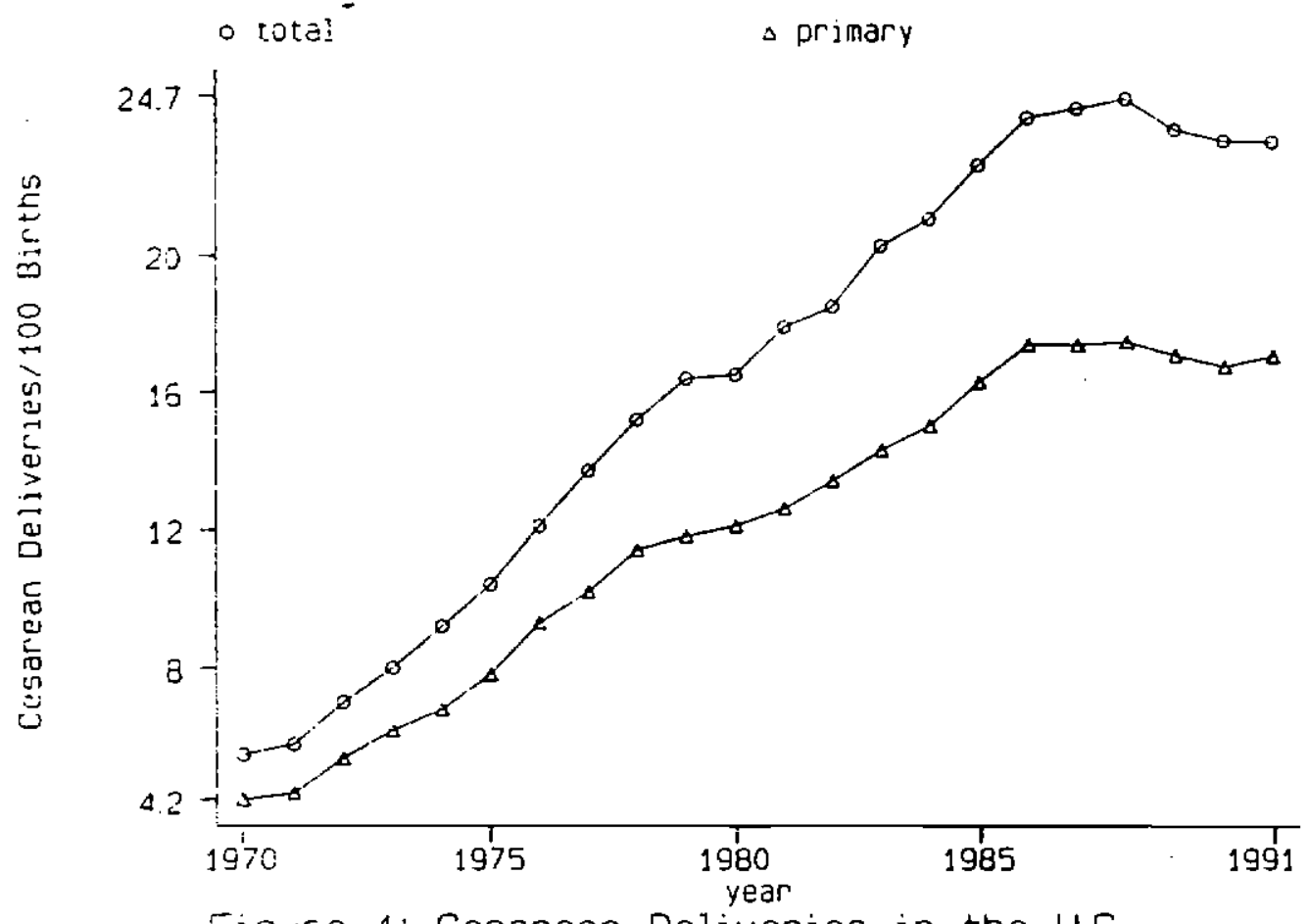

Figure 1: Cesarean Deliveries in the U.S. 


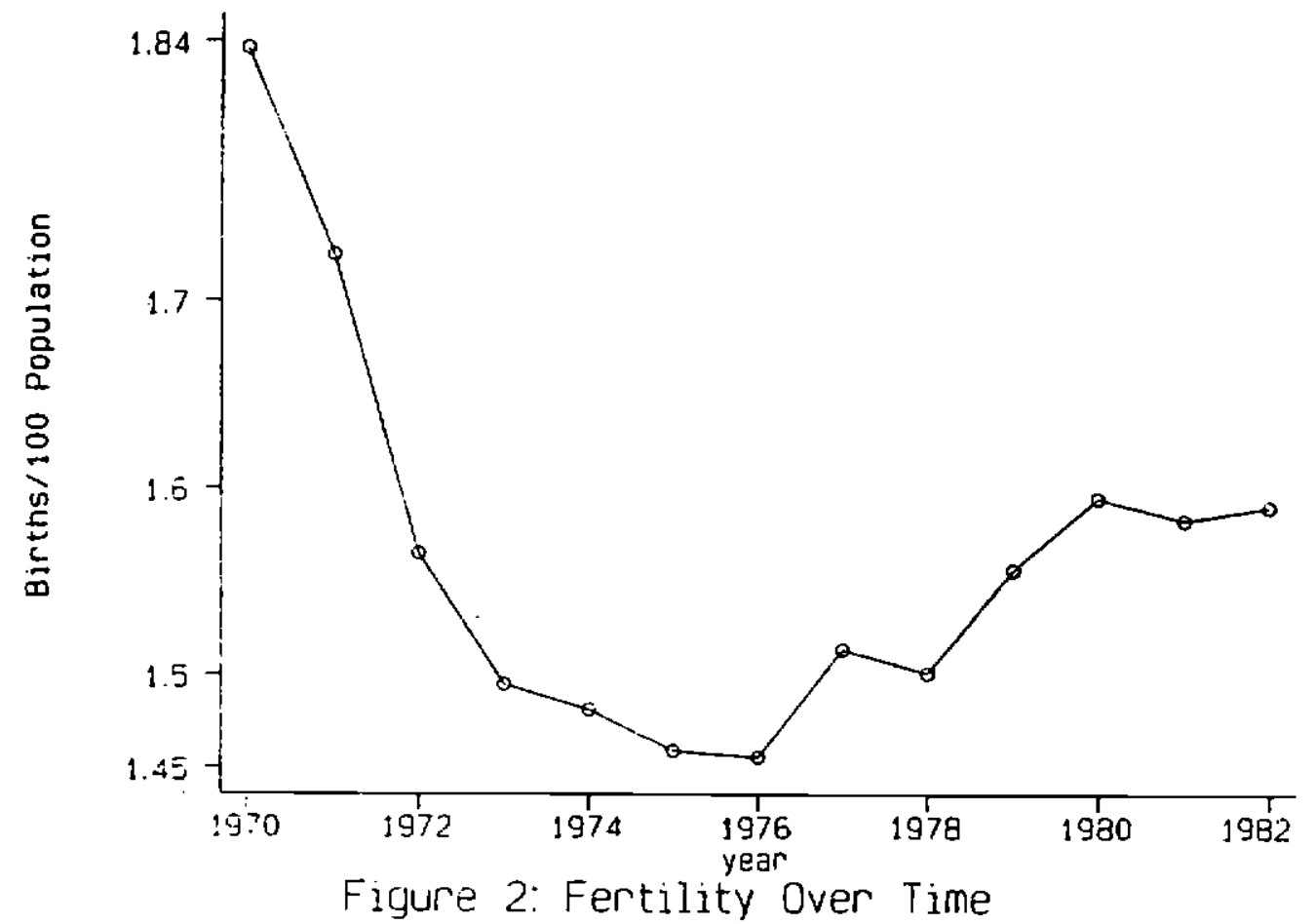




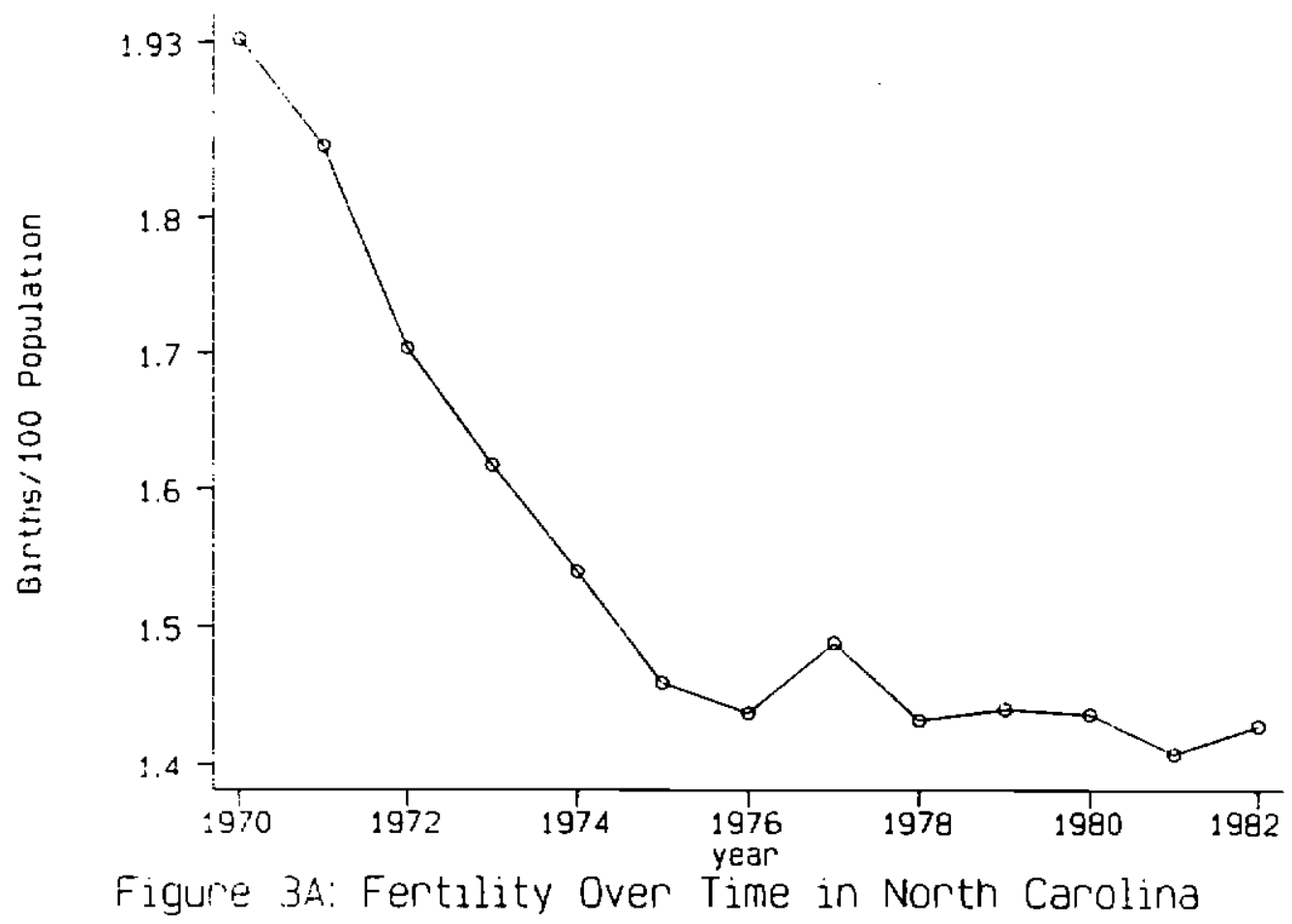




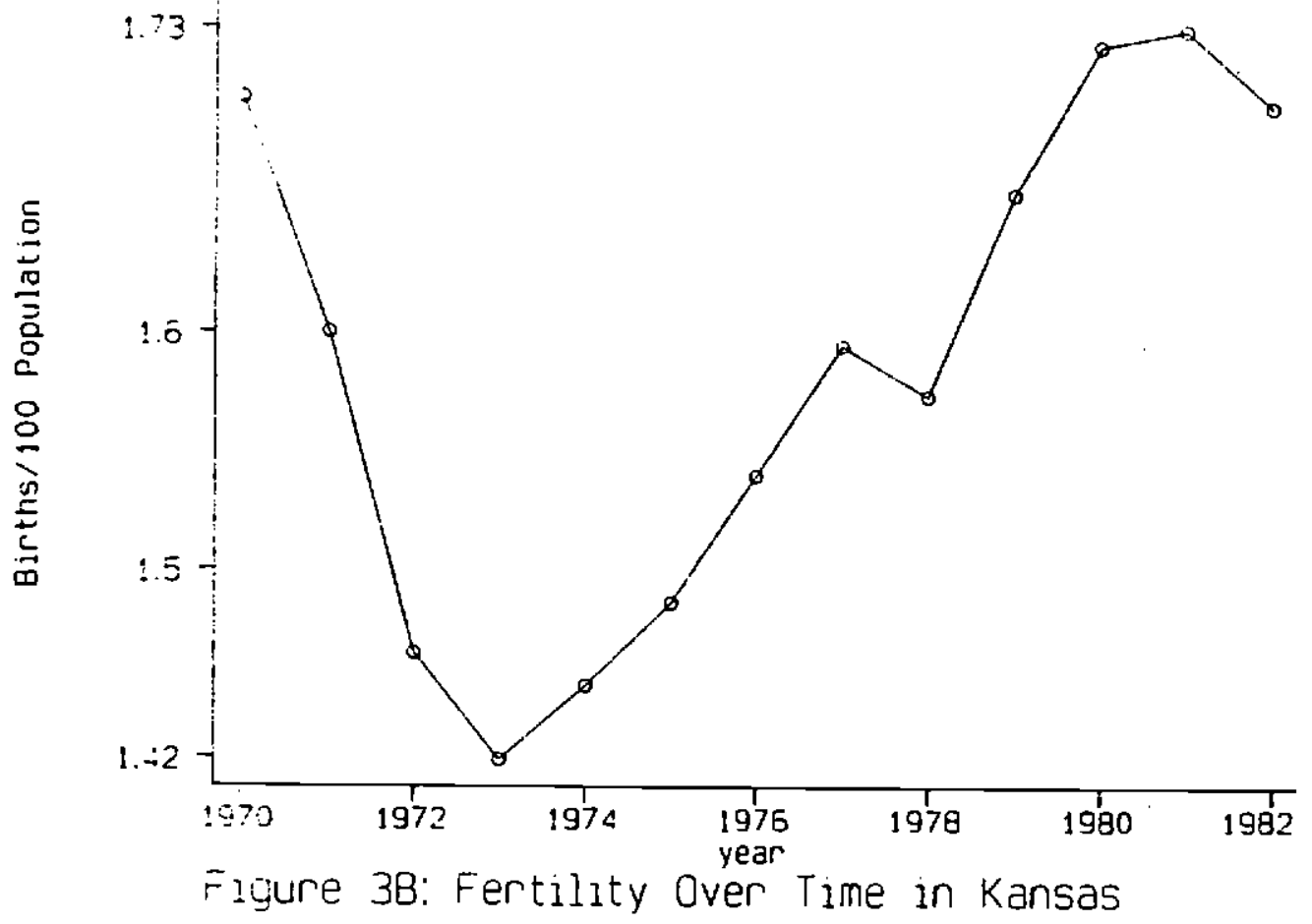




\begin{tabular}{|c|c|c|c|c|}
\hline \multicolumn{5}{|c|}{$\begin{array}{l}\text { Table A1: Verying the Specificatiod of Birthe/Fertility } \\
\text { Dependent Vuriable is a Dummy for Cesarean Delivery }\end{array}$} \\
\hline & (1) & (2) & (3) & (4) \\
\hline Log Births & $\begin{array}{l}-0.447 \\
(0.121)\end{array}$ & $\begin{array}{r}-0.908 \\
(0.208)\end{array}$ & & \\
\hline Log Population & & $\begin{array}{c}0.852 \\
(0.312)\end{array}$ & & \\
\hline $\begin{array}{c}\text { Log Fertility } \\
\text { (Birthd } 100 \text { population) }\end{array}$ & & & $\begin{array}{l}-0.923 \\
(0.201)\end{array}$ & \\
\hline Fertility & & & & $\begin{array}{l}-0.516 \\
(0.124)\end{array}$ \\
\hline
\end{tabular}

Notes: Standard errors in pareatheses. All regressions include ox of regressors preseated in Table 2, tong with full set of state and year dummies. All regressions run as logits. Dependent variable is cesarean noction dummy. $\mathbf{N}=255,593$. 